\title{
Experiment and Simulation Study on the Amorphous Silicon Photovoltaic Walls
}

\author{
Wenjie Zhang, ${ }^{1}$ Bin Hao, ${ }^{2}$ and Nianping $\mathrm{Li}^{1}$ \\ ${ }^{1}$ College of Civil Engineering, Hunan University, Changsha, Hunan 410082, China \\ ${ }^{2}$ Center for Science and Technology of Construction, Ministry of Housing and Urban-Rural Development, Beijing 100835, China
}

Correspondence should be addressed to Nianping Li; linianping@126.com

Received 2 May 2014; Revised 7 July 2014; Accepted 21 July 2014; Published 27 August 2014

Academic Editor: Hongxing Yang

Copyright (C) 2014 Wenjie Zhang et al. This is an open access article distributed under the Creative Commons Attribution License, which permits unrestricted use, distribution, and reproduction in any medium, provided the original work is properly cited.

\begin{abstract}
Based on comparative study on two amorphous silicon photovoltaic walls (a-Si PV walls), the temperature distribution and the instant power were tested; and with EnergyPlus software, similar models of the walls were built to simulate annual power generation and air conditioning load. On typical sunshine day, the corresponding position temperature of nonventilated PV wall was generally $0.5 \sim 1.5^{\circ} \mathrm{C}$ higher than that of ventilated one, while the power generation was $0.2 \% \sim 0.4 \%$ lower, which was consistent with the simulation results with a difference of $0.41 \%$ in annual energy output. As simulation results, in summer, comparing the PV walls with normal wall, the heat per unit area of these two photovoltaic walls was $5.25 \mathrm{kWh} / \mathrm{m}^{2}$ (nonventilated) and $0.67 \mathrm{kWh} / \mathrm{m}^{2}$ (ventilated) higher, respectively. But in winter the heat loss of nonventilated one was smaller, while ventilated PV wall was similar to normal wall. To annual energy consumption of heating and cooling, the building with ventilated PV wall and normal wall was also similar but slightly better than nonventilated one. Therefore, it is inferred that, at low latitudes, such as Zhuhai, China, air gap ventilation is suitable, while the length to thickness ratio of the air gap needs to be taken into account.
\end{abstract}

\section{Introduction}

Solar energy is regarded as the world's richest renewable resource with the broadest distribution. In the circumstances where energy security and climate change remain critically important, the solar power generation technology drew increasing attention from various countries with the enhancing strategic importance. In addition to the development of large-scale ground photovoltaic (PV) power stations in the suburbs, the application of PV in buildings is also considered to be prospects in crowded urban area $[1,2]$.

Based on the differences of PV modules serving as buildings components, there are two forms divided roughly, the building-integrated photovoltaics (BIPV) and the buildingattached photovoltaics (BAPV) [3]. Despite whatever form is taken, the reconstituted building envelope contributed by the integration of PV modules, compared to the normal building envelope, is varied in terms of structures, thermal performance [4-6], and so on, which will further influence the indoor cooling and heating load of the buildings $[7,8]$ as well as the performances of PV modules [9-11], such as the decline of photoelectric conversion efficiency due to the increase of the panel temperature rise.

Photovoltaic wall (PV wall), as a common form of PV applied in buildings, the optimum design scheme and operation strategies were extensively studied. Yang et al. [12] established the heat transfer model of the PV wall. One-dimensional unsteady heat conduction equation was emphasized to simulate the heat gain of the PV wall and to compare it with that of the normal wall without PV modules. This research took concrete cases into account in order to investigate the summer heat gain of the PV wall. The result turned out to be that the PV modules will increase the temperature of the air gap in PV wall while it is producing electricity. However, the PV modules shelter from solar radiation functioned to lower down substantially the outdoor comprehensive temperature while reducing the heat gain of walls in summer. The final result would be the reduction of 


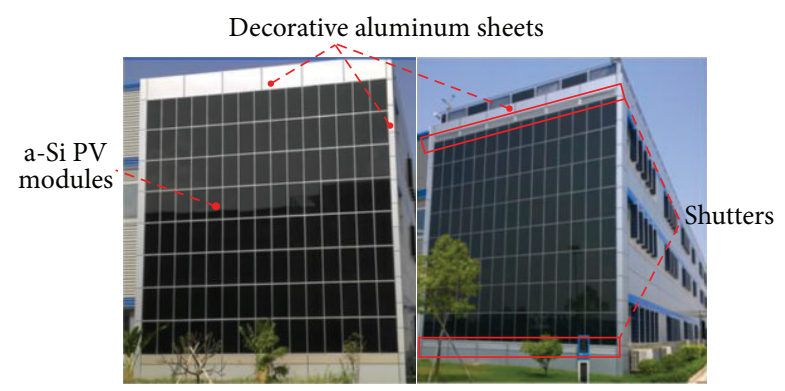

(a) Nonventilated PV wall (b) Ventilated PV wall

FIGURE 1: The two amorphous silicon PV walls under experiment.

the indoor cooling load of air conditioning. While, there is no description about the direction and location(latitude) of the PV wall.

Ji et al. [13-15] launched the comparison between the PV walls with air gap and the one with no air gap in terms of the electricity generation efficiency and indoor heat gain. The comparison experimental platform was constructed for the convenience of comparing the above-mentioned PV walls which were facing the west with different cooling methods. Respective mathematical models also were constructed. Based on the comparison of the experiments and calculation regarding the two types of PV walls, the result suggested that in Hong Kong these two cooling methods demonstrated nearly no differences in terms of electricity generation efficiency. However, with respect to the indoor heat gain, both methods substantially are different compared with each other. The problem is that the literature has not revealed the exact PV module types that were used in the experiments while the mathematical models did not take the relationship between the temperature rise of the PV panel and the electricity generation efficiency into account.

Zhu et al. [16] adopted the foamed plastic sheets as the simulated walls to make a box as the building and several bulbs displayed evenly as the simulated sunshine. Meanwhile, they came up with a model that was based on the temperature integral which can be used to investigate and simulate the multiheat exchange inside the PV walls. The result was congruent with the expected value. Concurrently, through comparison, it was found that the cooling down efficiency of the ventilated PV walls was $7 \%$ to $10 \%$ higher than that of the nonventilated ones. Certainly, this conclusion was drawn in the indoor experimental conditions, which meant that there may be certain limits in the real situation.

There is a plenty of comparative research over the thermal performance of the PV walls with different structures, analyzing the influence on the PV system efficiency and the indoor cooling and heating load; however, those were based on the constructed experiment equipment or real-scale experimental models. This research also conducted the comparison among the temperatures, immediate power under the positive sunshine condition, and generating capacity of each part of two PV walls based on the measurements on parameters of these two PV walls (one of them has the closed air gap between the PV modules and the walls while the other has the open air gap with shutters to have air flows) like temperature, electricity generating power, and generating capacity. In addition, this research also resorted to the emulated software in order to build the models of the two PV walls and the conventional walls and compared the possible influence of the generating capacity of the two PV walls and the three walls on the indoor air conditioning load.

\section{The PV Walls}

The study is carried out on two PV walls in two buildings, respectively, which are the same at construction and functions in Zhuhai, China (coordinates: N22.378, E113.547), as Figure 1 shows. These two PV walls are identical in terms of the configuration, numbers, connecting ways of the electric system, wall materials, and size. They only slightly differ from each other with regard to the structure.

2.1. Structure. Similarities between two PV walls are as follows:

(1) They are vertical to the ground, $5^{\circ}$ south by east.

(2) They are identical in terms of the building design structure size and functions. The inner sides of the PV walls are office areas which can be divided into three floors; there is a meeting room in each floor.

(3) The overall size of the wall is $12.25 \mathrm{~m}(\mathrm{H}) \times 10.2 \mathrm{~m}(\mathrm{~L})$, among which the size of the PV modules is $10.2 \mathrm{~m}$ $(\mathrm{H}) \times 9.8 \mathrm{~m}(\mathrm{~L})$. Other parts are constituted by the decorative aluminum sheets. The lower edge of the PV modules is $1.2 \mathrm{~m}$ away from the ground.

(4) There are $10 \mathrm{~mm}$ gaps between the PV walls. In order to make sure that the air gap in the back of the PV wall will not be influenced, the silicone weatherproofing sealant is used to fill the gap between modules.

(5) There are no buildings in the front side. There is a $4 \mathrm{~m}$ distance between the PV walls and the surrounding plants. No shadow is cast on the PV modules.

(6) They are both in PV wall structure with air gap between the modules and the walls. The air gap is at thickness of $155 \mathrm{~mm}$. Due to the horizontal steel sheet used to hang the PV modules, part of the air gap is only thick at $90 \mathrm{~mm}$. For details refer to Figure 2 .

What makes them different is the processing in the higher and lower edges of the two PV walls. The airless one (Figure 1(a)) closed the higher and lower edges by the aluminum sheets. The air gap of the back did not open to the outside. The ventilated one (Figure 1(b)) adopted the shutters in the higher and lower edges so that the air gap of the back of the PV modules can communicate with the outside. There are six groups of shutters, respectively, in the higher and lower positions, each of which has a size at $1600(\mathrm{~L}) \times 405(\mathrm{H})$.

2.2. PV System. The electric systems of two PV walls are independent of each other. Each wall is constituted by 120 a-Si PV modules with $40 \mathrm{Wp}$ (refer to Table 1 for details of 


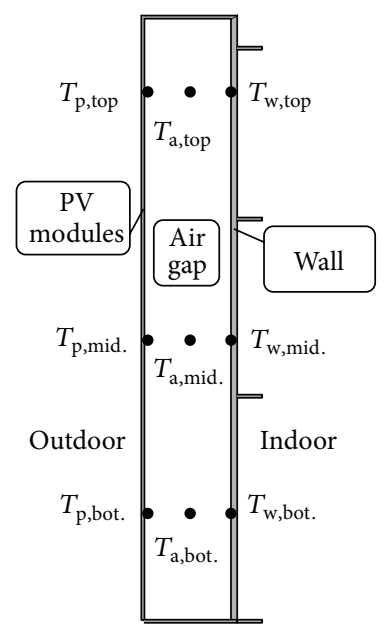

(a) Nonventilated PV wall

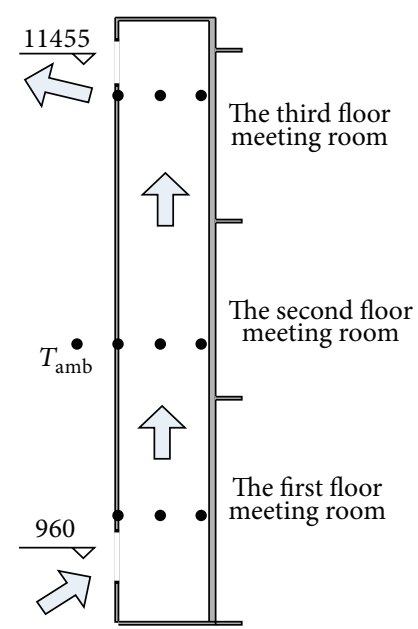

(b) Ventilated PV wall

Figure 2: Diagram of the two PV walls' structure and the temperature sensor points.

parameters). The installed power of the system is $4.8 \mathrm{~kW}$. Vertically, each row has $8 \mathrm{PV}$ modules, which composed a group string. There are 15 group strings in total, which go through the combiner box and get connected to the grid by an inverter. The maximum input direct-current power of the inverter is $3200 \mathrm{Wp}$ while the maximum input direct-current voltage is $550 \mathrm{~V}$. The MPPT voltage ranges from $125 \mathrm{~V}$ to $550 \mathrm{~V}$.

\section{Experiment Study}

3.1. Testing Parameters and Measure Points. The sensors that were used to measure the outdoor environmental parameters were deployed in the roof of the ventilated PV wall. No obstructions were found. The measured parameters included the temperature and the humidity of the outdoor weather, the wind direction and speed, and the solar radiation in the vertical and horizontal directions. The irradiating apparatus used to test the vertical direction was deployed on the surface where the PV modules were installed.

The panel temperature, temperature of the air gap, and the surface temperature of the wall were measured on the central axis of the vertical direction of the PV wall at different positions (the higher, middle, and lower positions). In addition, the temperatures of the exit and entrance for the air flow of the shutters in the higher and lower edges of the ventilated PV wall would also be tested. The measure points' positions were shown in Figure 2.

The instant current values and the instant voltage values of two PV systems would be measured and recorded in the inverter. Meanwhile, the cumulative generating capacity was also measured.

3.2. Measure System and Sensors. In order to continuously measure and record the above-mentioned parameters, the multichannel sensor would be connected to the itinerant detector. See Figure 3. Each parameter would be inspected through the itinerant detector which would send the data to
TABLE 1: The parameters of the a-Si PV modules used in the project.

\begin{tabular}{lc}
\hline Parameters & Information or value \\
\hline Manufacturer & CG solar \\
Model number & CGS-40H/G1245 $\times 635$ \\
Maximum power at STC $\left(P_{\max }\right)$ & $40 \mathrm{~W}$ \\
Tolerance & $\pm 5 \%$ \\
Open circuit voltage $\left(V_{\mathrm{oc}}\right)$ & $60.5 \mathrm{~V}$ \\
Short circuit current $\left(I_{\mathrm{sc}}\right)$ & $1.16 \mathrm{~A}$ \\
Maximum power voltage $\left(V_{\mathrm{mp}}\right)$ & $43.8 \mathrm{~V}$ \\
Maximum power current $\left(I_{\mathrm{mp}}\right)$ & $0.92 \mathrm{~A}$ \\
Maximum system voltage & $\leq 600 \mathrm{~V} \mathrm{DC}$ \\
Maximum fuse rating & $2 \mathrm{~A}$ \\
Length $(\mathrm{mm})$ & 1245 \\
Width $(\mathrm{mm})$ & 635 \\
Thickness $(\mathrm{mm})$ & 7 \\
\hline
\end{tabular}

TABLE 2: Parameters of the major sensors used in testing.

\begin{tabular}{ll}
\hline Sensors & Parameters \\
\hline & $\begin{array}{l}\text { Directional response: less than } \pm 10 \mathrm{~W} \cdot \mathrm{m}^{-2} \\
\text { (for } 1000 \mathrm{~W} \cdot \mathrm{m}^{-2} \text { beam radiation) } \\
\text { Temperature response: } 1 \% \text { (within an } \\
\text { interval of } 50^{\circ} \mathrm{C} \text { ) } \\
\text { Pyranometer }\end{array}$ \\
& $\begin{array}{l}\text { Nonlinearity: } \pm 0.2 \% \text { (from } 100 \text { to } \\
1000 \mathrm{~W} \cdot \mathrm{m}^{-2} \text { ) }\end{array}$ \\
& Spectral range: 300 to $2800 \mathrm{~nm}$ \\
\hline \multirow{2}{*}{$\begin{array}{l}\text { Thermal resistance } \\
\text { Pt100 }\end{array}$} & $\begin{array}{l}\text { Division value: } 0.1^{\circ} \mathrm{C} \\
\text { Accuracy: } \leq \pm 0.5 \%\end{array}$ \\
\hline $\begin{array}{l}\text { Direct-current } \\
\text { electricity energy }\end{array}$ & Response time: $\leq 10 \mathrm{~S}$ \\
sensor & Range: $0 \sim 200 \mathrm{~V} / 0 \sim 10 \mathrm{~A}$ \\
& Division value: $1 \mathrm{mV} / 1 \mathrm{~mA}$ \\
& Accuracy: $\leq \pm 0.5 \%$
\end{tabular}

the computer for loading and storage. The time interval for the recording is 1 minute. Due to the far distance between two 


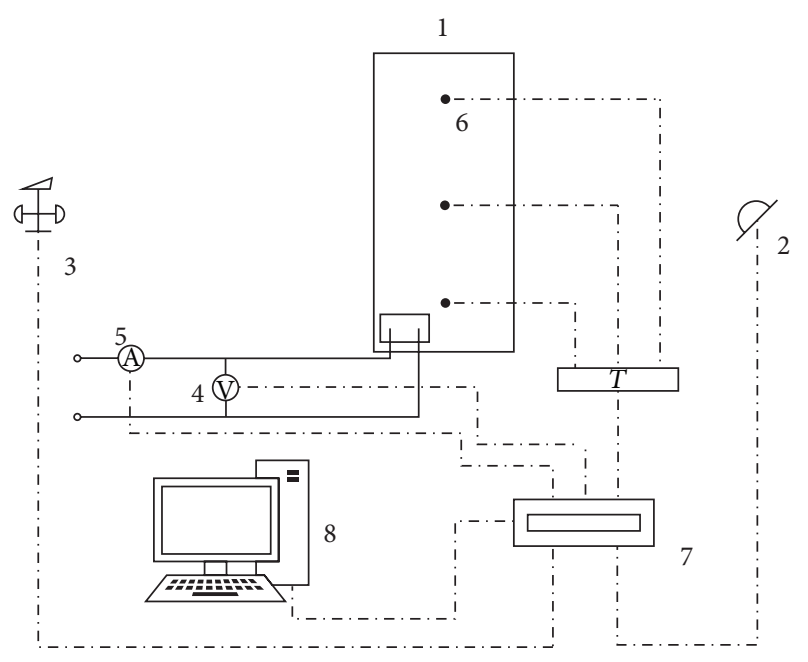

FIGURE 3: The thermal performance measure system with the ventilated PV wall. 1: PV wall; 2: pyranometer; 3; sensors for wind direction, speed, temperature, and humidity; 4: volumeter; 5: ampere meter; 6: temperature probe; 7: itinerant detector; 8: computer.

PV walls, two measure systems like this have been deployed in two PV walls in order to reduce the length of the Pt100 thermal resistance wire. Figure 3 showed the measure system in ventilated PV wall with the sensors to measure the outdoor environmental parameters.

Table 2 showed the sensor parameters which could influence the measure accuracy in the test.

\section{Experiment Result Analysis}

4.1. The Comparison of the Temperatures between the Panel, Wall Surfaces, and Air Gap of the PV Walls. Launch the analysis over the temperature fields of each measure point in the PV panel, outer wall surfaces, and air gap with typical sunshine condition day (Jan. 20, 2014). See Figures 4, 5, and 6. Due to the differences between the order of heat transmission and the heat storage capacity, the following features would be displayed.

(1) The change of the temperature curves procrastinated to respond to the change of the sunshine in 0.5-2 hours, among which the wall surface temperature was most obvious. The possible reason came down to the order of heat transmission and the specific heat.

(2) In the daytime with normal sunshine condition, put the temperature from high to low: panel, air gap, and wall surface. The temperature of the panel is $5-7^{\circ} \mathrm{C}$ higher than that of the wall surface and $3-5^{\circ} \mathrm{C}$ higher than that of the air gaps. In the sunset or night, the order was as follows: wall surface, air gap, and panel. They all had the $1-2^{\circ} \mathrm{C}$ disparity among each other due to the differences of their heat storage capacity and heat dissipation.

(3) The temperatures for closed air gap, due to the thermal inertia, displayed the temperature from 6:30 to $8: 30$ which was $2-3^{\circ} \mathrm{C}$ lower than the environmental temperature. From 8:30 to 14:00, the temperature was almost identical to the environmental one while, from 14:00 to $6: 00$, the temperature was $1-2^{\circ} \mathrm{C}$ higher than the environmental one.

(4) There would be the quick temperature rise in the panel after the sun rose while the temperature of the panel quickly went consistent with the environment after the sunset. Afterwards, till the sun rose again, the temperature kept identical with the environment.

(5) The peak of the temperature of the panel and air gaps was at 15:30. The one of the wall surface was at 17:00.

(6) The temperature curves in ventilated PV wall had a similar relationship and features with those of the nonventilated PV wall. However, the temperature disparities of the measure points were smaller than those of nonventilated PV wall.

4.2. The Comparison of the Temperature Field in Vertical Direction. Figure 6 shows the temperature of the panel of the nonventilated PV wall in the vertical direction. Take three points with the same distance in the bottom, middle, and top of the wall. Conspicuously, in the sunshine condition, the temperature disparity between the bottom and the middle parts was about $2-3^{\circ} \mathrm{C}$ while the one between the middle and top parts was only $0.5-1.5^{\circ} \mathrm{C}$, which demonstrated that the temperature rise in the vertical direction gradually declined. The analysis revealed that the observed decline shared certain correlation with the closed flow field. The heat was accumulated in the top, leading to the reduction of the temperature rise.

Figure 7 showed that the wall surface of nonventilated PV wall also had the same tendency of the decline of the temperature rise. The temperature disparity between the bottom and middle parts was at $2.5^{\circ} \mathrm{C}$ while the temperatures of the middle and the top parts were nearly the same with disparity only at $0.5-1^{\circ} \mathrm{C}$, which indicated that the temperature would be lower than the environment in sunshine condition while being higher than the environment without sunshine due to the thermal inertia and its position in the end of the heat transmission.

Figure 8 indicated that the wall in nonventilated PV wall also had the same tendency of the decline of the temperature rise in the vertical direction of the air gaps. The temperature disparity between the middle and bottom parts was at $2-4^{\circ} \mathrm{C}$ while that between the top and the middle parts was only $1-2^{\circ} \mathrm{C}$. The temperature in the bottom with no sunshine was almost identical with the environment. When the environment temperature got rise due to the sunshine and the bottom temperature was lower than it. The situation of the temperature of the middle part was as stated above: the closed air gaps, due to the thermal inertia, had the lower temperature than the environment, probably at $2-3^{\circ} \mathrm{C}$, from $6: 30$ to $8: 30$. The temperature kept identical with the environment from 8:30 to $14: 00$ while being higher than the environment at 1$2^{\circ} \mathrm{C}$ from 14:00 to 6:00. The temperature at top was always higher than the environment. 


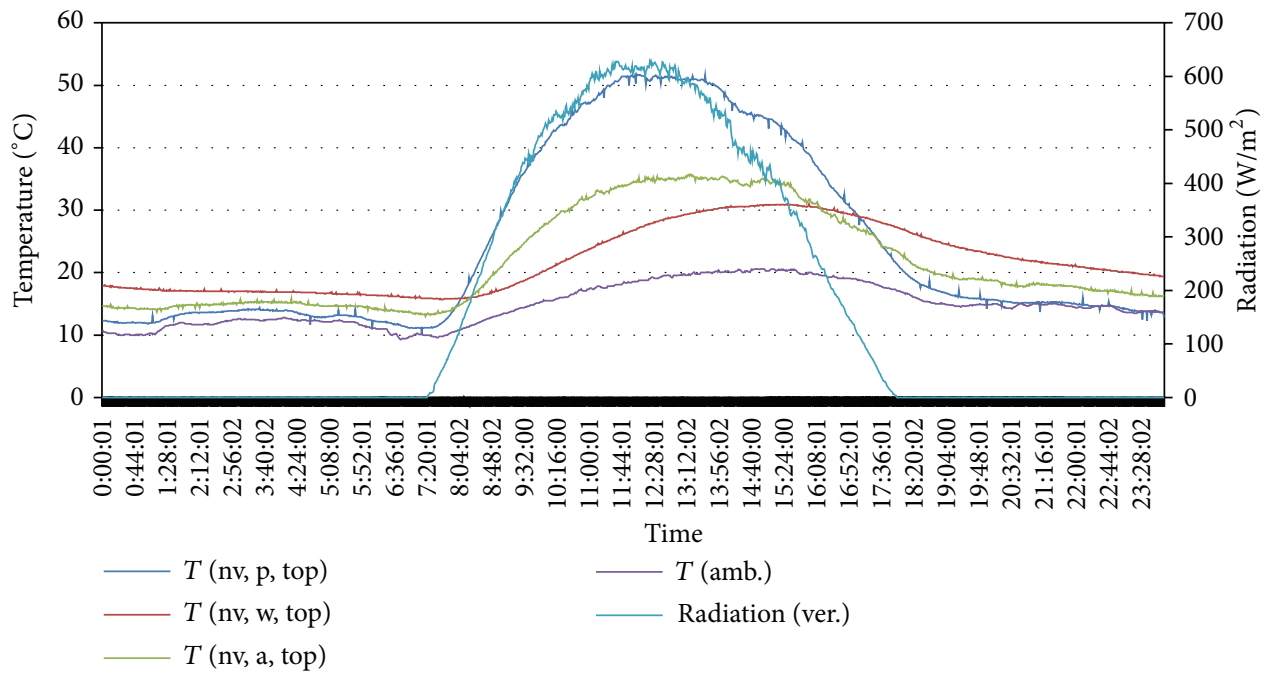

FIGURE 4: The temperature of different points (the top of panel, outer wall, and air gap) of the nonventilated PV wall under the typical sunshine condition.

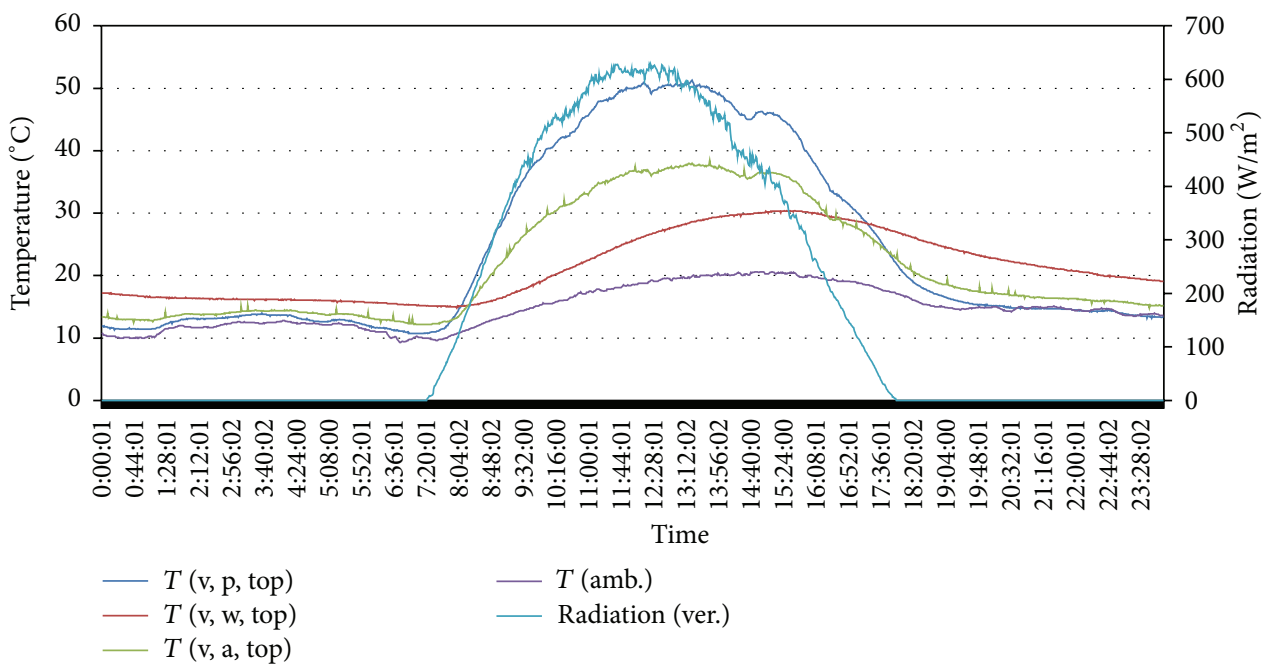

FIGURE 5: The temperature of different points (the top of panel, outer wall, and air gap) of the ventilated PV wall under the typical sunshine condition.

4.3. The Comparison of the Temperature between Nonventilated $P V$ Wall and Ventilated $P V$ Wall. The different approaches were taken to process the top and bottom edge of the nonventilated PV wall and ventilated PV wall. The difference of air gap led to the different influence of their temperature fields.

As shown by Figure 9, with sunshine condition, the temperature disparity of the panel at top in nonventilated PV wall and ventilated PV wall was only $0.5-1.5^{\circ} \mathrm{C}$. Nonventilated PV wall was the higher one. The largest disparity appeared before 14:00, after which the disparity got closed. After the sunset, nearly no disparity was observed.

Figure 10 showed that there would be certain temperature disparity between the wall surface of the top of nonventilated PV wall and ventilated PV wall. In the daytime with sunshine, the temperature of nonventilated $\mathrm{PV}$ wall was generally higher at $2^{\circ} \mathrm{C}$ but dropped to $1^{\circ} \mathrm{C}$ after the sunset.
Figure 11 showed that the temperature of the air gap at top of the nonventilated PV wall was always higher than that of ventilated PV wall at $2^{\circ} \mathrm{C}$, which declined early in the morning.

4.4. The Comparison of the Electricity Generation between Nonventilated PV Wall and Ventilated PV Wall Systems. In Figure 12 the comparison of the relations between output power and panel temperature of the two kinds of PV walls in the typical sunshine is shown. From it, we can see that, from 9:20 to 14:30, the panel temperature of ventilated PV wall is 0.5 to $1.5^{\circ} \mathrm{C}$ lower than that of nonventilated PV wall, while the output power is $0.2 \%$ to $0.4 \%$ higher than that of nonventilated PV wall; more obviously, from around 15:00 to $16: 00$, the panel temperature of ventilated PV wall fluctuates and turns out to be about $2^{\circ} \mathrm{C}$ higher than that 


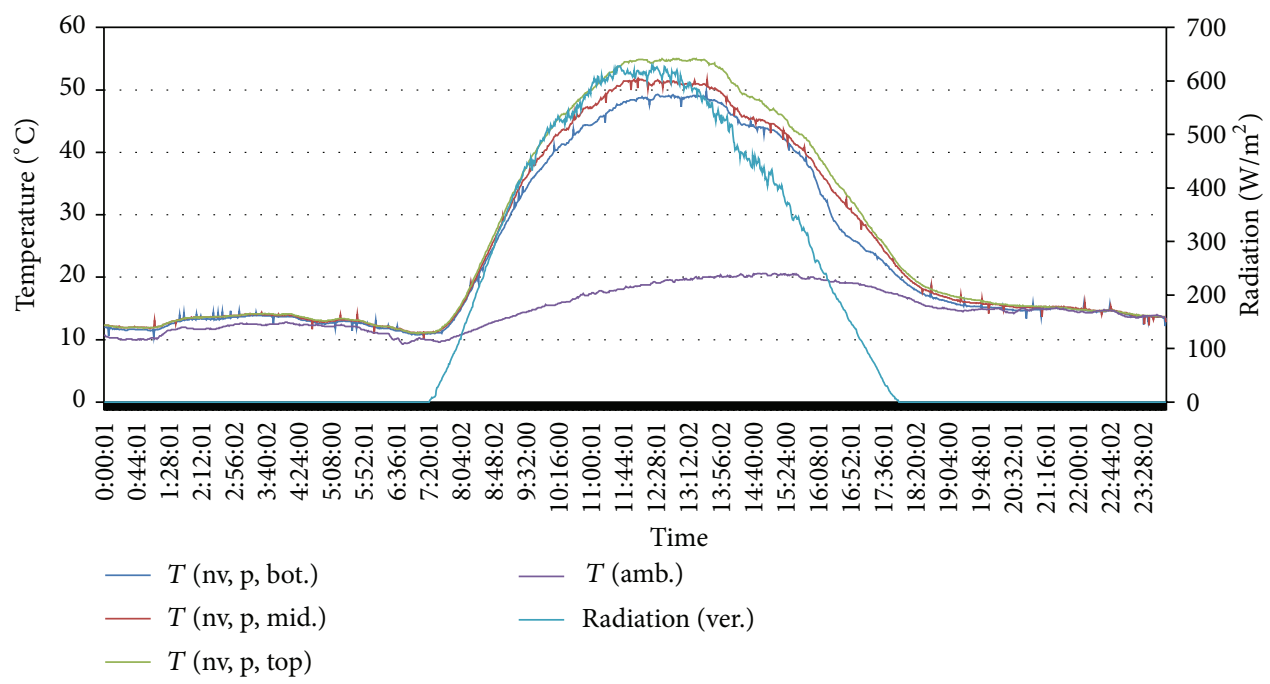

FIGURE 6: The temperature of different points (panel in vertical direction) of the nonventilated PV wall under the typical sunshine condition.

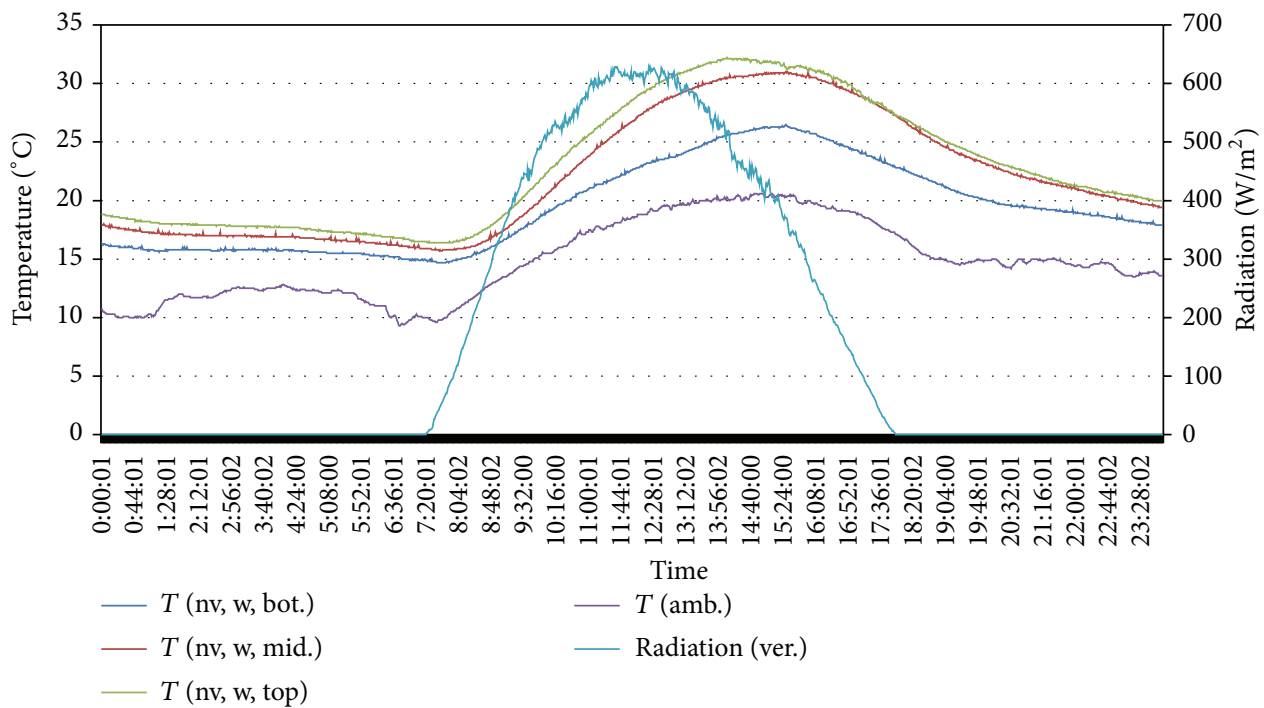

FIgURE 7: The temperature of different points (outer wall in vertical direction) of the nonventilated PV wall under the typical sunshine condition.

of nonventilated PV wall, along with which its generating efficiency significantly drops and is about $0.5 \%$ lower than that of nonventilated PV wall. For both of the systems, the peak output power occurs at 12:30 when the solar irradiance reaches a higher value of the day and is $3.351 \mathrm{~kW}$ and $3.337 \mathrm{~kW}$, respectively. The generated energy throughout the day of the nonventilated is $18.71 \mathrm{kWh}$ and of the ventilated is $18.78 \mathrm{kWh}$; there is a difference of $0.07 \mathrm{kWh}(0.37 \%)$ between the two. The panel temperatures of both PV walls do not seem to be much different from each other and thus the difference of their power is smaller.

\section{Simulation Study}

5.1. Model Establishment. EnergyPlus Model cannot simulate only the energy cost of buildings, but also the electricity generation of the PV system. In order to overall investigate the electricity generation of the PV walls and their influence on the indoor air conditioning energy cost, this research adopted the EnergyPlus software to simulate the data of the electricity generation and heat transmission performance in the domestic meteorological year.

First, model the system is based on the PV walls and the exact size of buildings. Figure 13 showed the pictures of the airless PV walls, the ventilated PV walls, and the ordinary walls. The air vents at top and bottom of the ventilated PV walls were in form of four windows that could be opened. Within these windows, there were venetian blinds which shared the same size with the exact shutters in order to simulate the ventilation effect of the shutters. The EnergyPlus software had three models that simulated the solar energy electricity generation system, which are Simple 


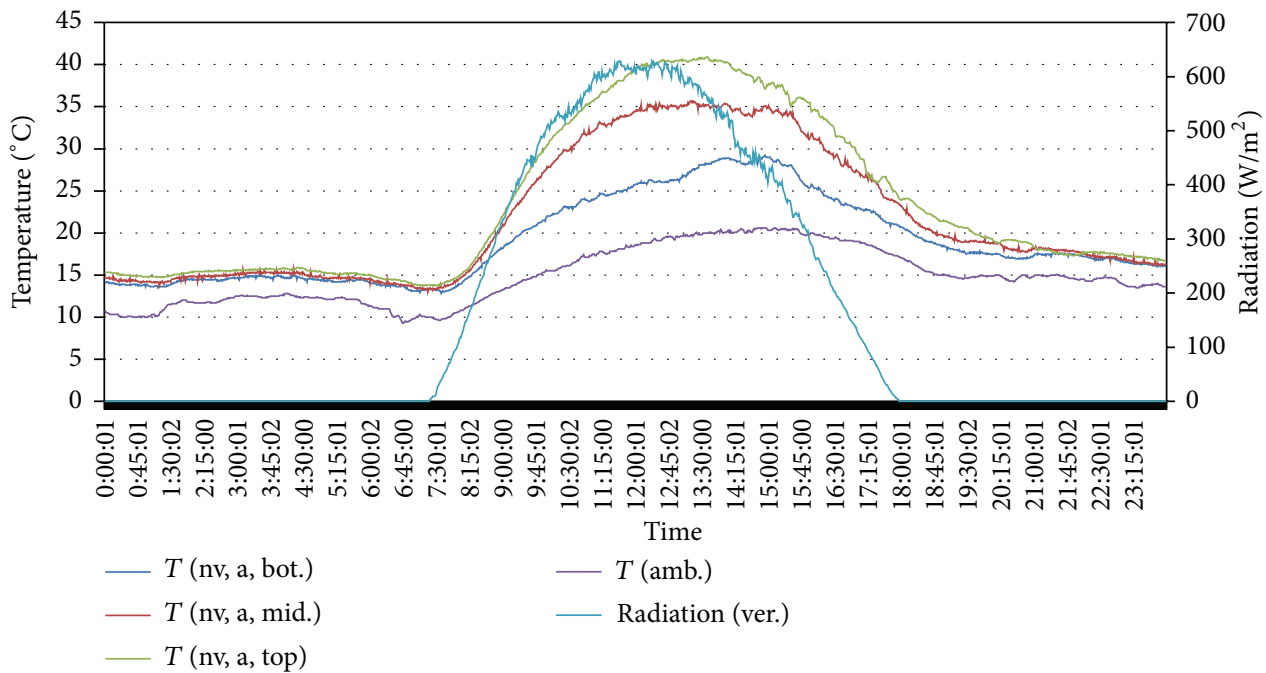

FIGURE 8: The temperature of different points (air gap in vertical direction) of the nonventilated PV wall under the typical sunshine condition.

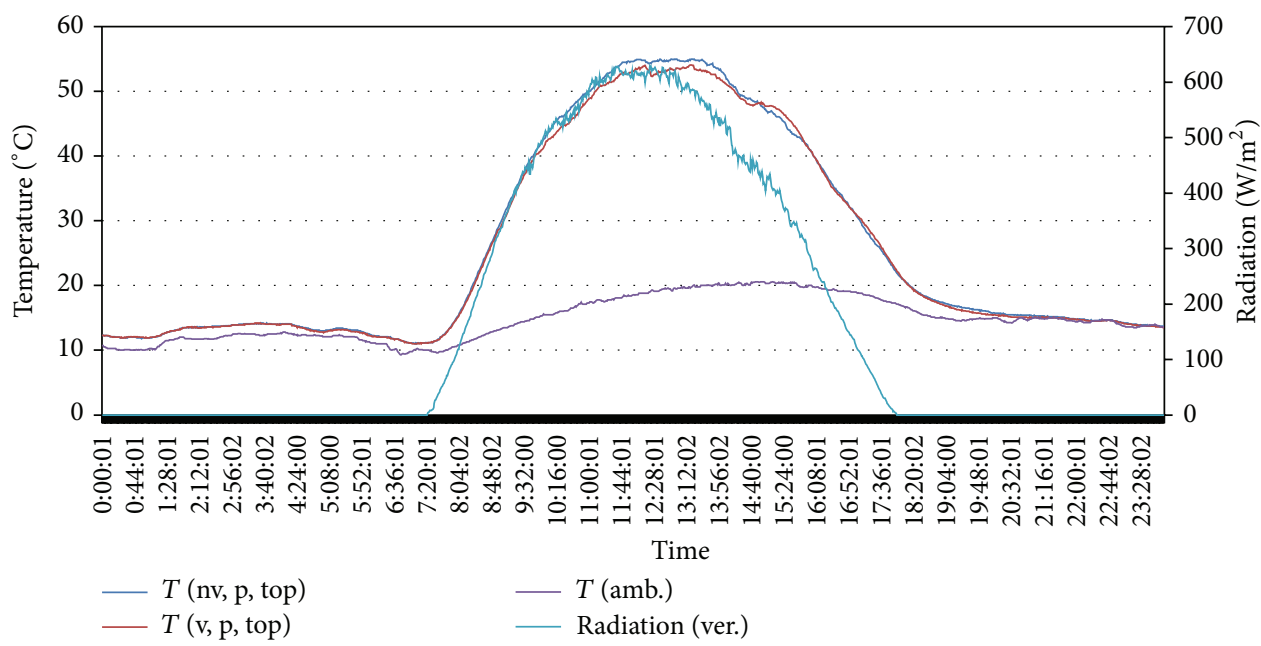

FIGURE 9: The panel temperature comparison at the top of nonventilated PV wall and ventilated PV wall.

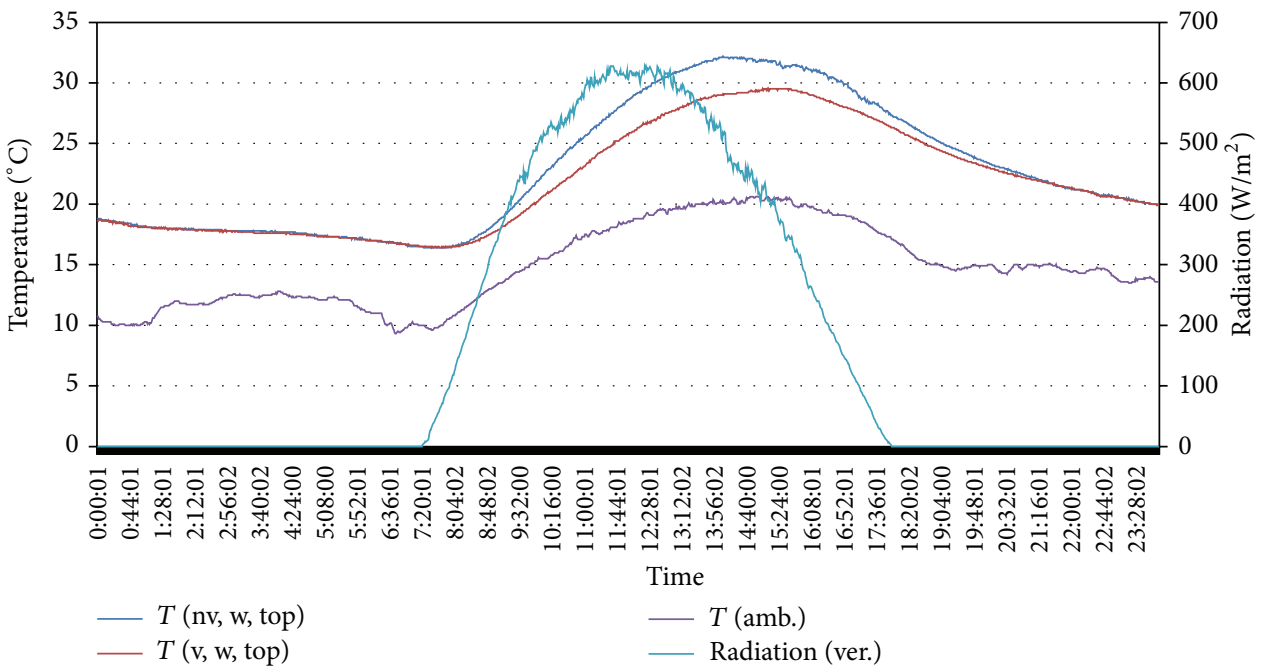

FIgURE 10: The outer wall temperature comparison at the top of nonventilated PV wall and ventilated PV wall. 


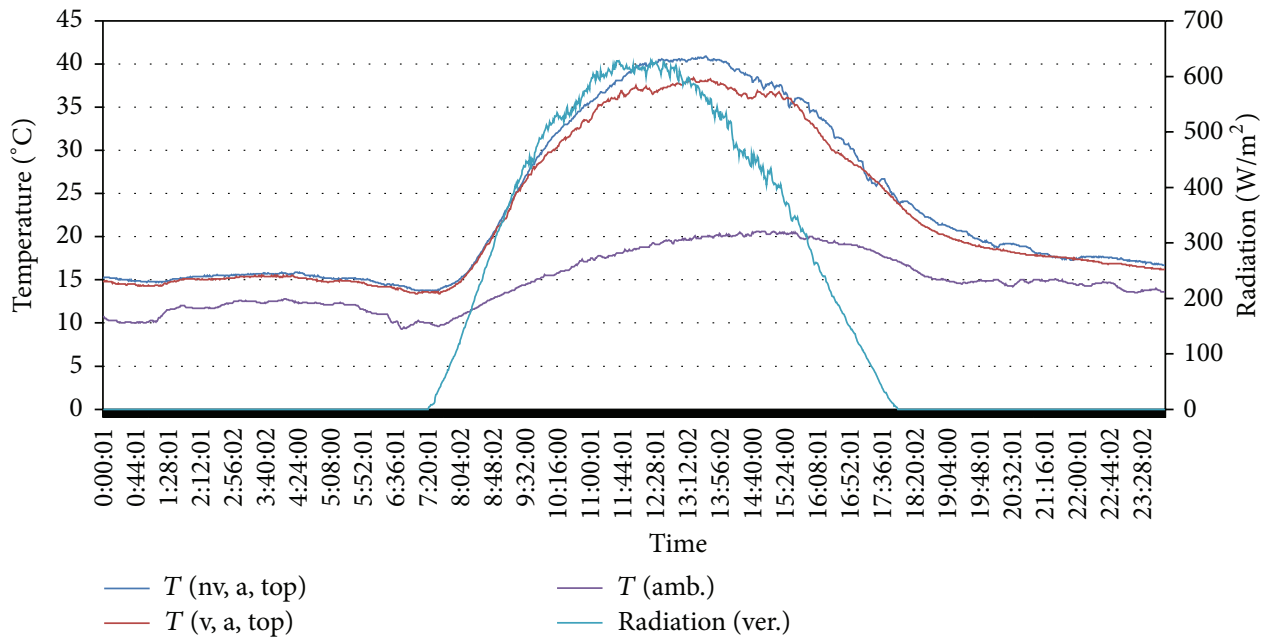

FIGURE 11: The air gap temperature comparison at the top of nonventilated PV wall and ventilated PV wall.
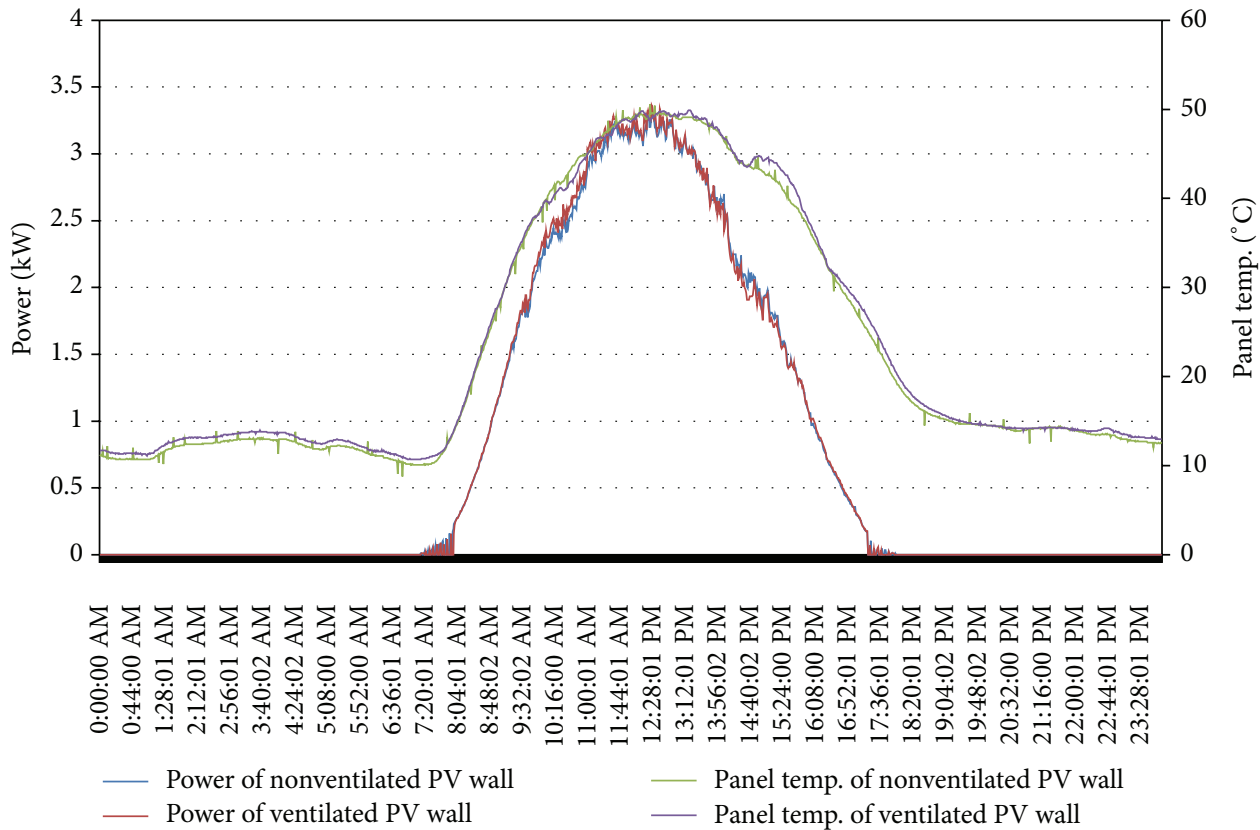

FIGURE 12: The comparison of the relations between output power and panel temperature of nonventilated PV wall and ventilated PV wall.

Model, Equivalent Diode Circuit Model, and Sandia Model. The Comparison among these three revealed that Sandia PV Model had the best effect of simulating the a-Si PV walls. Therefore, this research adopted the Sandia PV Model to simulate the dynamic electricity generation capacity of the PV walls. A plenty of the parameters used in the model were from the special indoor and outdoor tests over the same aSi PV modules in order to guarantee the accuracy of the simulation. In an attempt to investigate the influence of the air gaps on the PV module temperature and the indoor heat transmission volumes, the Airflow Network Model in the EnergyPlus was adopted to simulate the air flow and the heat transfer features between the PV walls and normal walls.
5.2. Model Verification. In order to verify the accuracy of the model, some key parameters like the solar radiation, operating temperature of the components, wall surface temperature, and system direct-current output power would be verified through experiment. The experiment was conducted from 18th to 25th of January of 2014 (8 days in total). To simulate the solar radiation at each time point was the first step as well as the most important step for the entire simulation, as it may determine the electricity generation capacity simulation of the PV walls and their influence on the indoor air conditioning load.

Figure 14 showed the comparison between simulated solar radiation from the south and the measured value. 


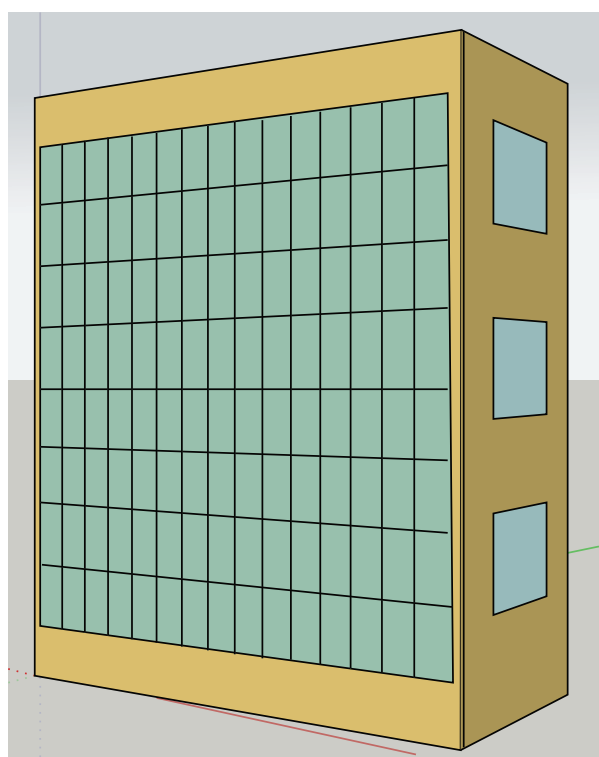

(a) Nonventilated PV wall

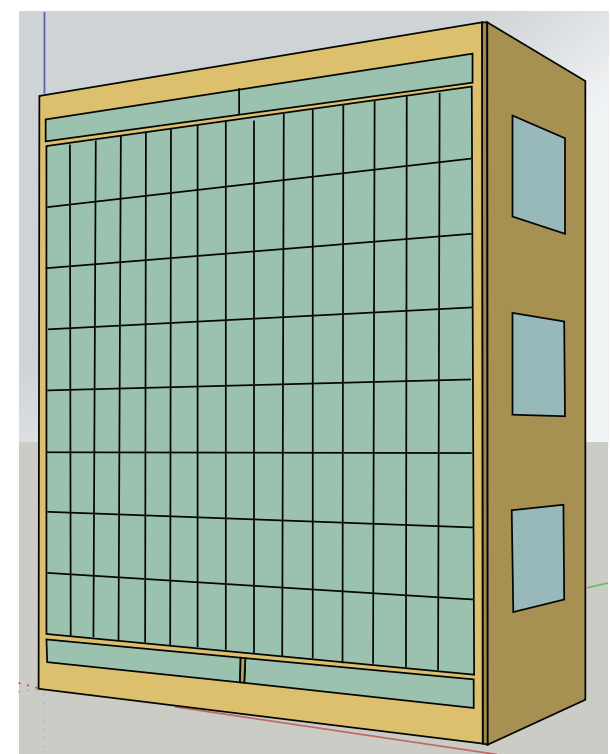

(b) Ventilated PV wall

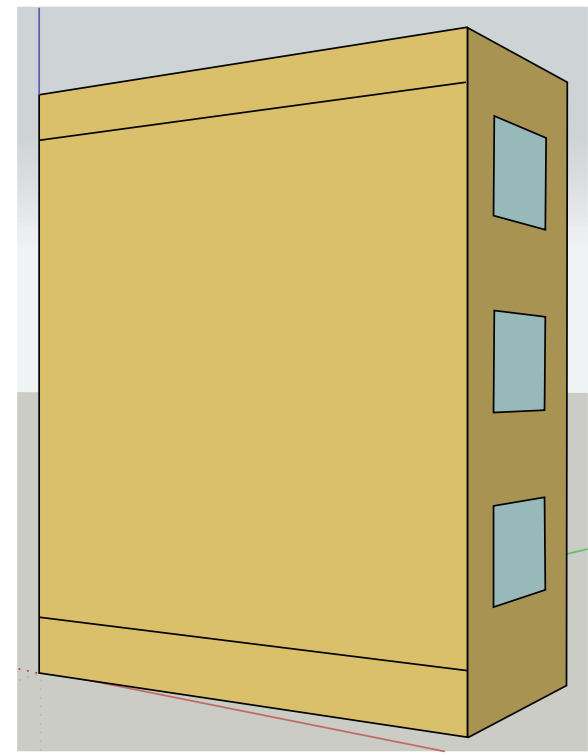

(c) Normal wall

FIGURE 13: Schematic of simulation models with three different wall structures.

It is easy to discover that the simulated values were higher than the exact measure value in the noon of the fine day. However, the errors fell into the acceptable range. In overcast days, the simulated values were perfectly identical with the exact number.

Figure 15 showed the comparison between the simulated direct-current electricity generation capacity and the measured value, which revealed that the simulated values were comparatively identical with the measurements with errors less than 4.4\%. It indicated that the Sandia PV Model used in this research could be the accurate simulation system for dynamic electricity generation power.

The temperature of the internal walls of the PV walls directly determined the indoor heat transmission volumes.
Therefore, this research also conducted the experiment to verify the simulated results.

Figure 16 showed the verification result of the outer wall simulated surface temperature of the ventilated PV wall, which suggested that, in most of time, the simulated surface temperature was consistent with the exact number. However, in some specific fine days, the temperature disparities were a little bit large. But even the largest temperature disparity was less than $3^{\circ} \mathrm{C}$, which was acceptable.

The operating temperature of the PV modules could directly determine the energy output of the PV walls. Figure 17 shows the comparison between the simulated panel temperatures of the PV modules and the exact numbers. Through this experiment, it is easy to discover that 


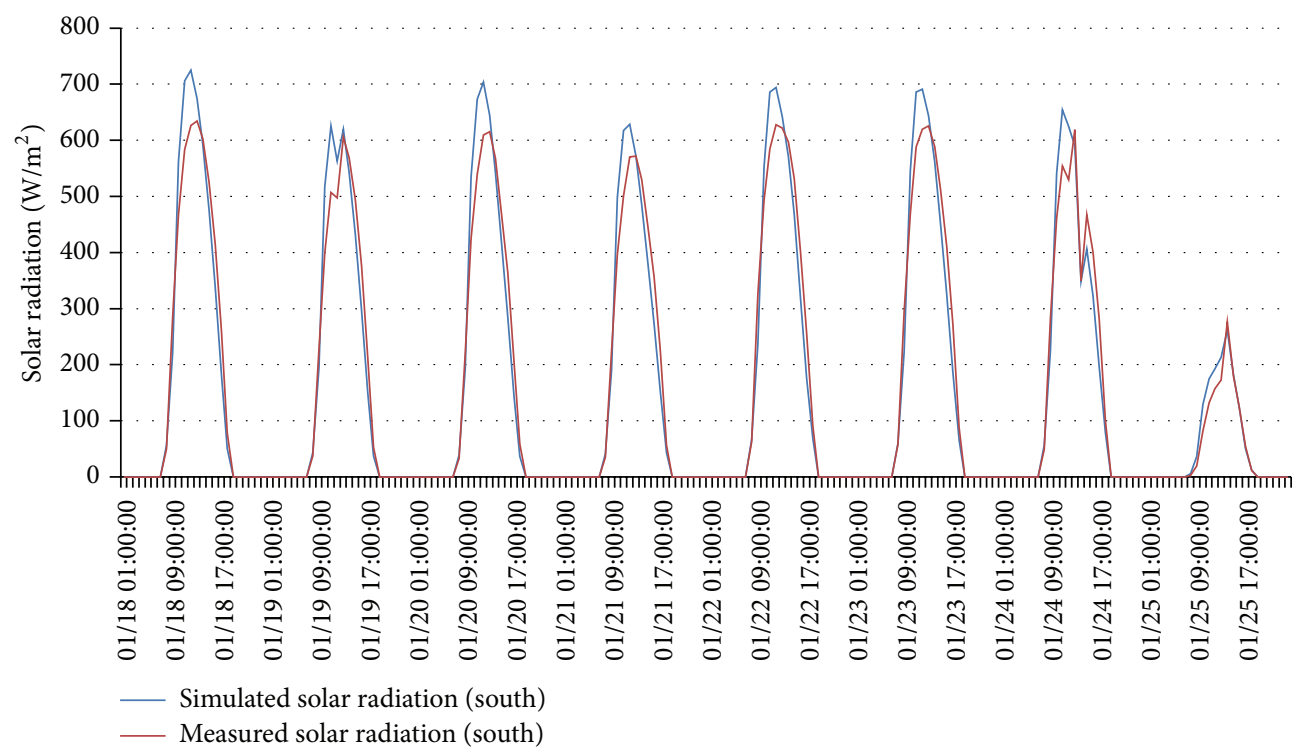

FIGURE 14: Comparison between the simulated solar radiation from the south and the measured value within the experiment days.

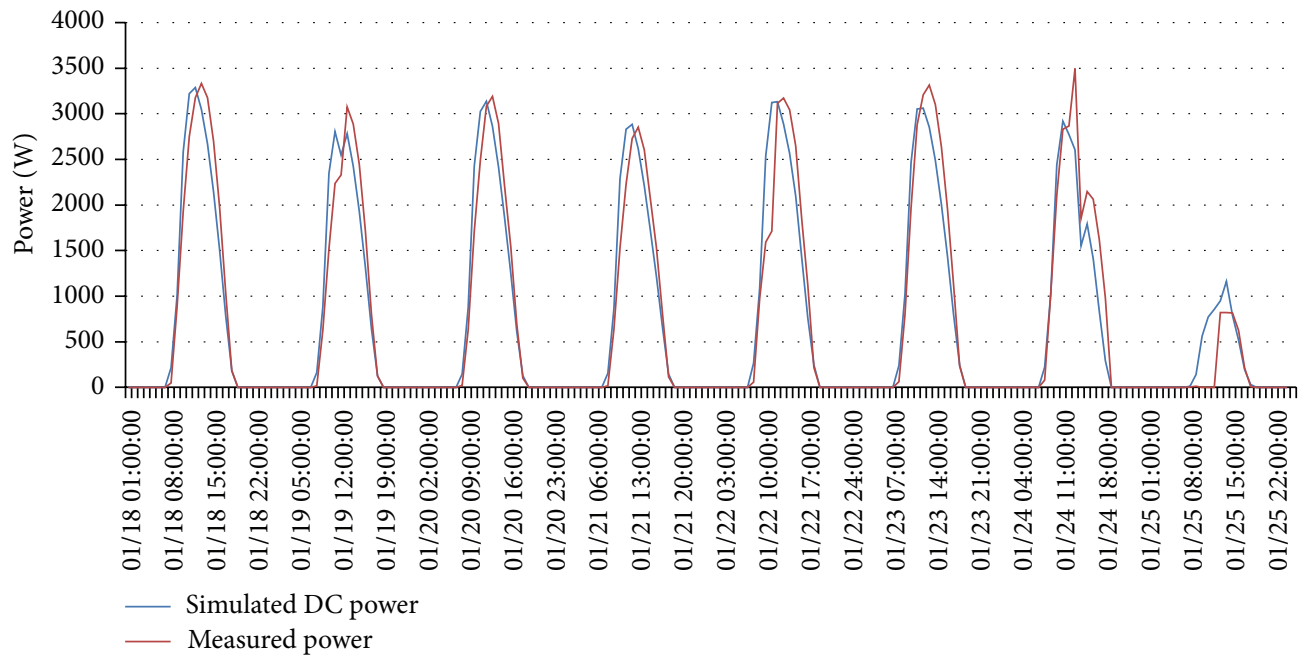

FIGURE 15: Comparison between the simulated electricity generation power and the measured value within the experiment days.

the simulated temperatures were generally lower than the exact ones. The largest temperature disparity was $5^{\circ} \mathrm{C}$. However, due to the small power temperature coefficient of the aSi PV modules which was generally $-0.25 \% /{ }^{\circ} \mathrm{C}$, the influence over the electricity generation capacity of the PV system was controlled to be about $-1 \%$ despite of the large temperature disparity at some times. This simulated temperature was also acceptable.

\section{Simulation Result Analysis}

6.1. The Comparison of Annual Electricity Generation Capacities. Figure 18 showed the annual electricity generation capacities of the simulated nonventilated PV wall model and the ventilated PV wall. According to Figure 18, the verified nonventilated PV wall model and the ventilated PV wall model simulated the electricity generation capacities of the two PV systems. From Figure 18, it is easy to find that the electricity generation capacity of the ventilated PV wall model was slightly higher than that of the nonventilated PV wall model. The disparity between the capacities of these two models was expanded from January to October in every year, probably by $0.5 \%$ to $0.7 \%$. The disparity was increased by $0.1 \%-0.2 \%$ in other months. The simulated results were as follows: the annual electricity generation capacity of the nonventilated PV wall model was about $2512.23 \mathrm{kWh}$ while that of the ventilated PV wall model was $2522.64 \mathrm{kWh}$. The observed disparity was $10.41 \mathrm{kWh}$, which was about $0.41 \%$.

6.2. The Comparison of Heat Gain and Building Energy Consumption with Different Structure Walls. In Zhuhai, May 1 to October 31 is the cooling season. Figure 19 displayed 


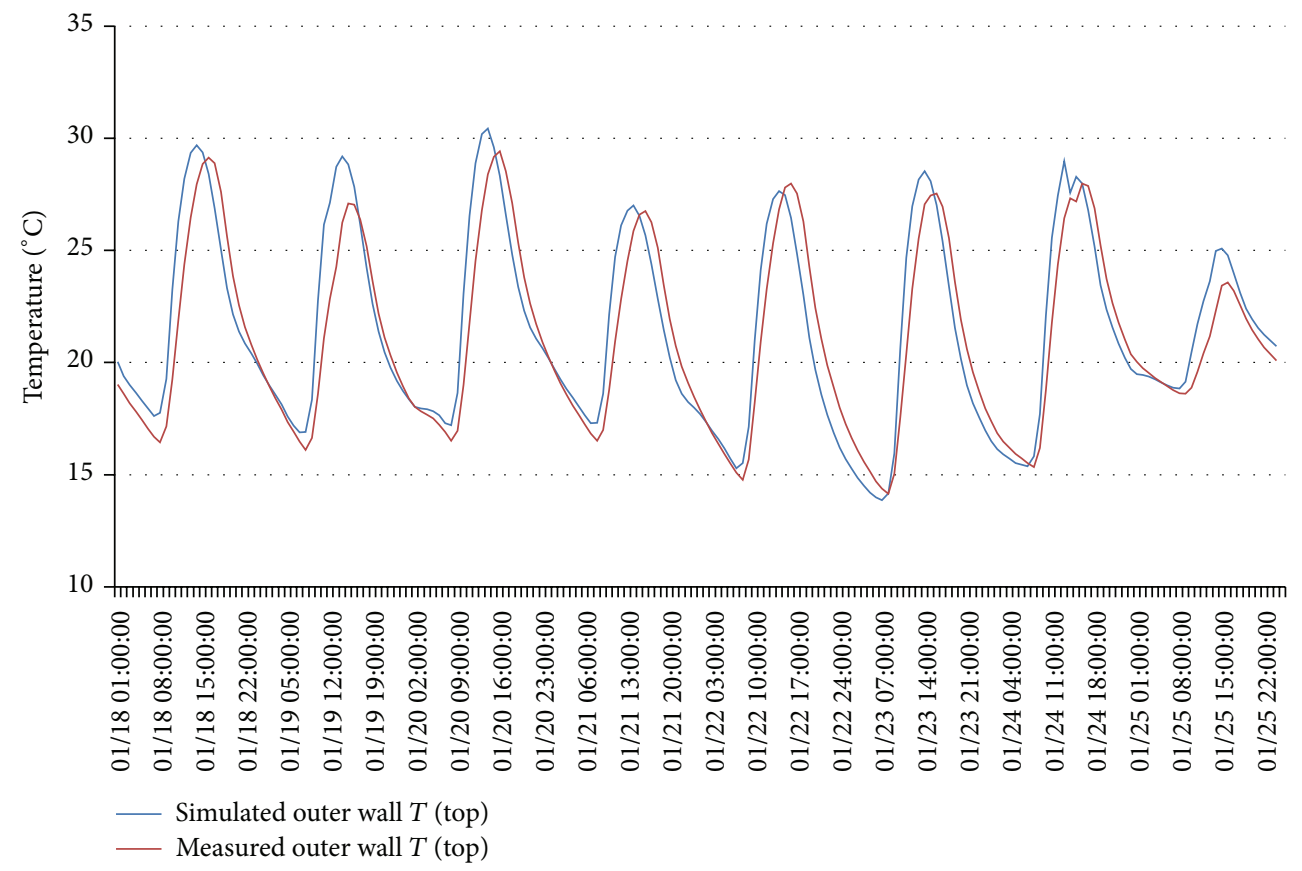

FIGURE 16: The comparison between the simulated outer wall surface temperature of the ventilated PV wall and the measured value within the experiment days.

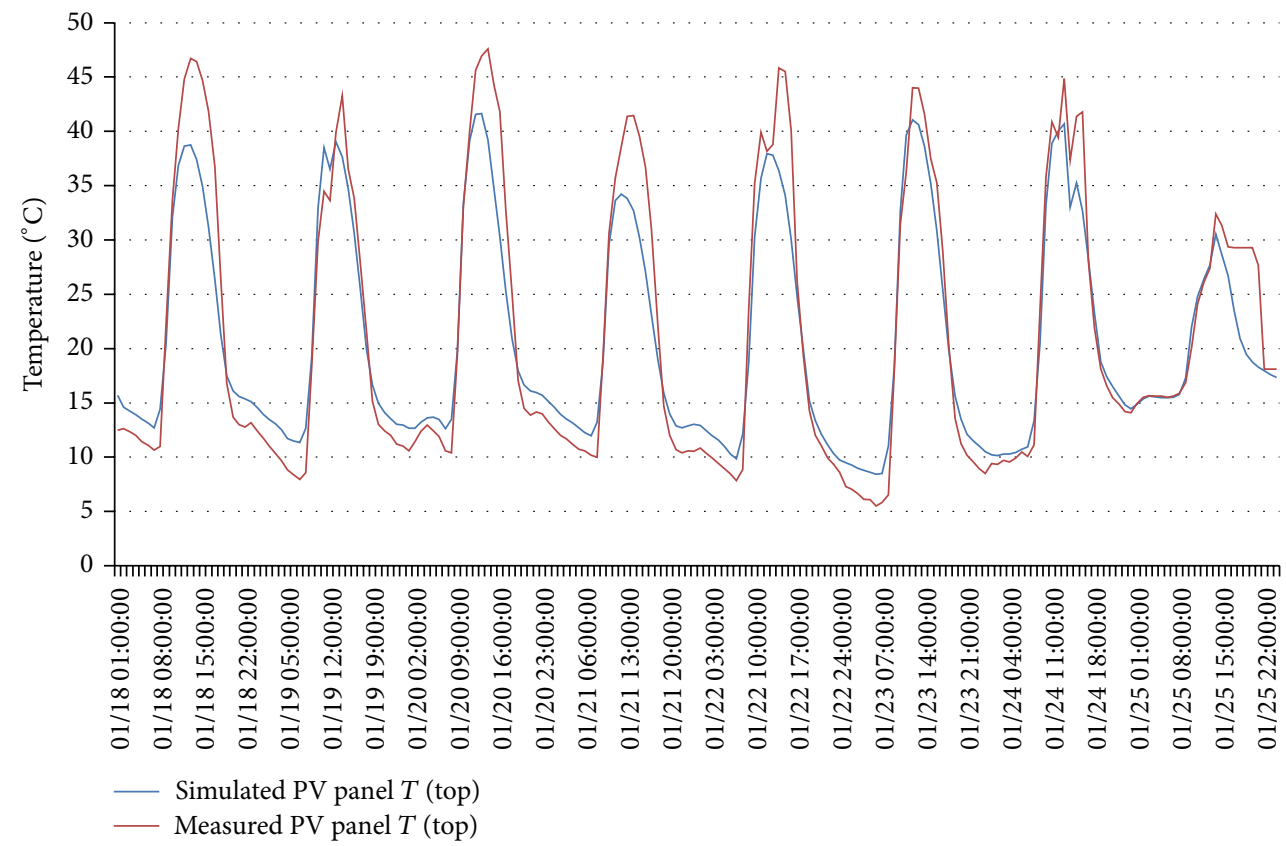

FIGURE 17: The comparison between the simulated panel temperature of the ventilated PV walls and measured value within the experiment days.

the conduction heat gain rate simulated of the nonventilated PV wall, ventilated PV wall, and normal wall during this period. Obviously, the heat gain of the nonventilated PV wall was larger than the ventilated one, especially from the end of September to the end of October. As Table 3 shows, Energy consumption for cooling of ventilated PV wall model is lower than that of nonventilated PV wall model by $6.03 \mathrm{kWh} / \mathrm{m}^{2}$ in summer.

Compared with the other two PV walls, the heat gain of the normal wall $\left(7.56 \mathrm{kWh} / \mathrm{m}^{2}\right)$ was actually $3.71 \mathrm{kWh} / \mathrm{m}^{2}$ less 
TABLE 3: Comparison of the annual building heating and cooling energy consumption between different models.

\begin{tabular}{lcccccc}
\hline \multirow{2}{*}{ Energy } & \multicolumn{2}{c}{ Nonventilated PV wall model } & \multicolumn{2}{c}{ Ventilated PV wall model } & \multicolumn{2}{c}{ Normal wall model } \\
& Heating & Cooling & Heating & Cooling & Heating & Cooling \\
\hline Electricity $\left(\mathrm{kWh} / \mathrm{m}^{2}\right)$ & 0 & 333.57 & 0 & 327.54 & 0 & 326.09 \\
Natural gas $\left(\mathrm{MJ} / \mathrm{m}^{2}\right)$ & 35.65 & 0 & 43.04 & 0 & 0 \\
\hline Total $\left(\mathrm{MJ} / \mathrm{m}^{2}\right)$ & & 1236.52 & & 1222.17 & 51.30 & 1225.21 \\
\hline
\end{tabular}

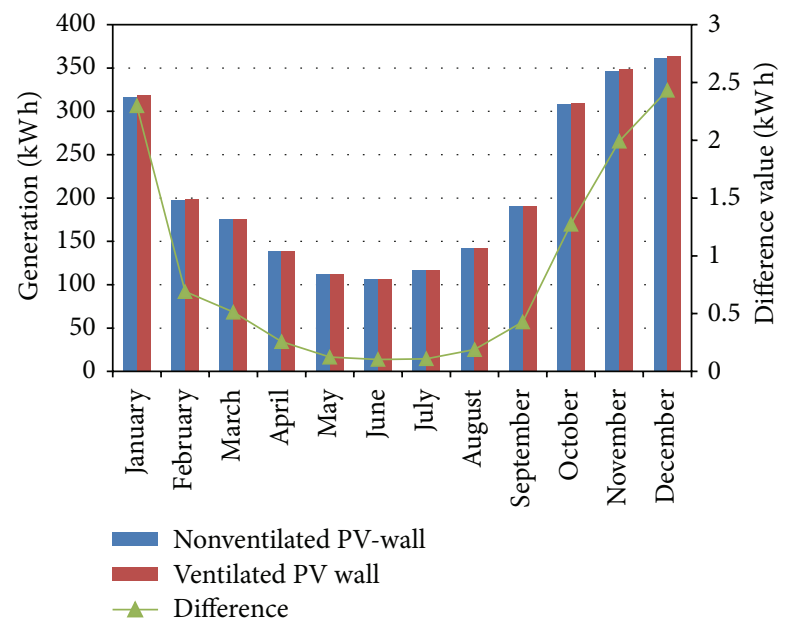

FIGURE 18: The comparison of annual electricity generation capacities month by month between nonventilated PV wall and ventilated PV wall with simulation.

than the nonventilated PV wall and $0.68 \mathrm{kWh} / \mathrm{m}^{2}$ less than the ventilated one within 6 months; that means the two PV walls increased building cooling load instead.

Similarly, as shown in Table 3 , according to the simulation result, the energy consumption of normal wall model for cooling is lower than the two PV wall models by $7.49 \mathrm{kWh} / \mathrm{m}^{2}$ and $1.45 \mathrm{kWh} / \mathrm{m}^{2}$, respectively.

There are two possible reasons for this result: on the one hand direct sun cannot shine on the south-facing wall for a long time in summer because of the local low latitude in Zhuhai; meanwhile due to the convective heat transfer effects between the normal wall and ambient air, the surface temperature is lower than PV wall for most of the daytime; another reason is probably that the absorption rate of normal wall is relatively lower, while that of the PV module is higher and regardless of whether the air gap is open to outer atmosphere, the heat in the air gap generated by PV panel cannot be effectively taken away but transmitted into the room through the wall. Specifically for the two PV curtain walls studied in this paper, the ratio of the height of PV wall (i.e., the length of the flow channel) to the thickness of air space (i.e., the distance between PV modules and walls) is much larger than such length to thickness ratio in the experimental apparatus used in laboratory experiments; meanwhile, in the practical engineering, there lay the structural support and electric power circuit in the air space, which will obstruct the air flow of the air layer and thus cannot achieve good ventilation and heat dissipation.
As shown in Figure 20, in winter (from November 1 to April 30 next year), the conduction heat loss rate of the normal wall $\left(17.69 \mathrm{kWh} / \mathrm{m}^{2}\right)$ is obviously larger than that of the ventilated PV wall by $1.75 \mathrm{kWh} / \mathrm{m}^{2}$ and nonventilated PV wall by $7.09 \mathrm{kWh} / \mathrm{m}^{2}$, respectively, which means that ranking of the building heat load in winter conditions for the three models was nonventilated PV wall, ventilated PV wall, and normal wall in descending order. The energy consumption in winter of the three models is shown in Table 3, which follows the same order as above.

According to Table 3 and comparison of these three models, ventilated PV wall model with normal wall model are similar at the annual total energy consumption of heating and cooling but slightly better than that of nonventilated PV wall model.

6.3. The Optimum Design Scheme and Operation Strategies with Different Structure Walls. Based on the above simulation results, some optimum design scheme and operation strategies for PV walls are proposed as follows.

(1) During the scheme design phase, deciding whether to adopt south-facing PV wall, it is necessary to estimate the impact on indoor cooling and heating load considering the latitude with different solar elevation angle.

(2) If we decide to adopt the south-facing PV wall, during the summer, the air gap between PV modules and walls may be ventilated, and the length to thickness ratio should be optimum designed to facilitate the air gap heat dissipation, to enable reduction indoor cooling load.

(3) And during the winter, the air gap may be nonventilated to reduce building heat loss.

(4) If there is only one status of the openings, the air gap ventilated or nonventilated can be decided by the annual cooling load and heating load.

\section{Conclusions}

Based on the above analysis of experimental and simulation results, the following conclusions can be drawn.

(1) In the typical sunshine condition, compared to the air gap of nonventilated PV wall, the air gap of the ventilated PV wall will be easier compared to cooling the PV panel and make the temperature lower than that of the nonventilated PV wall. As a result, the influence of the temperature rise of the 


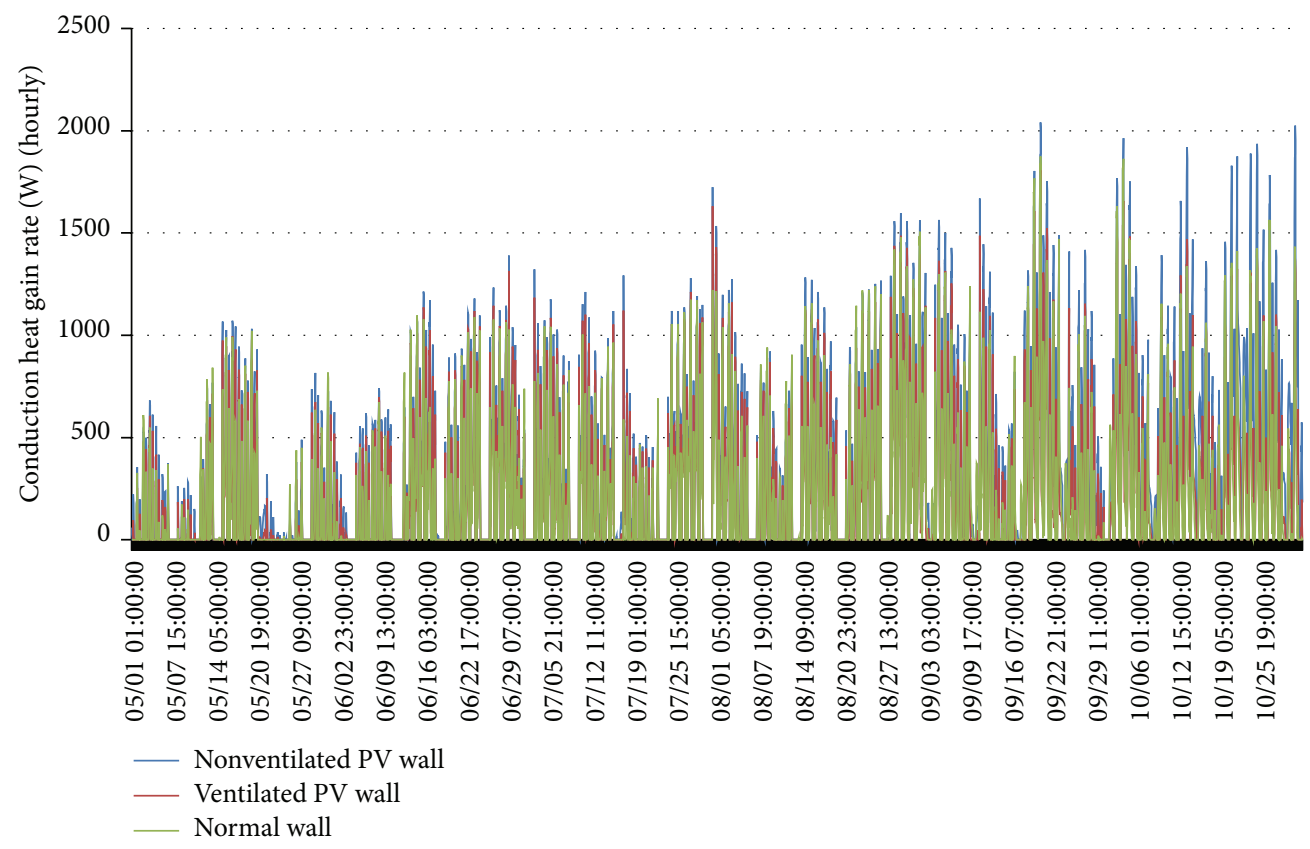

FIGURE 19: The comparison of the conduction heat gain rate between the nonventilated PV wall and the ventilated PV wall by simulation in summer.

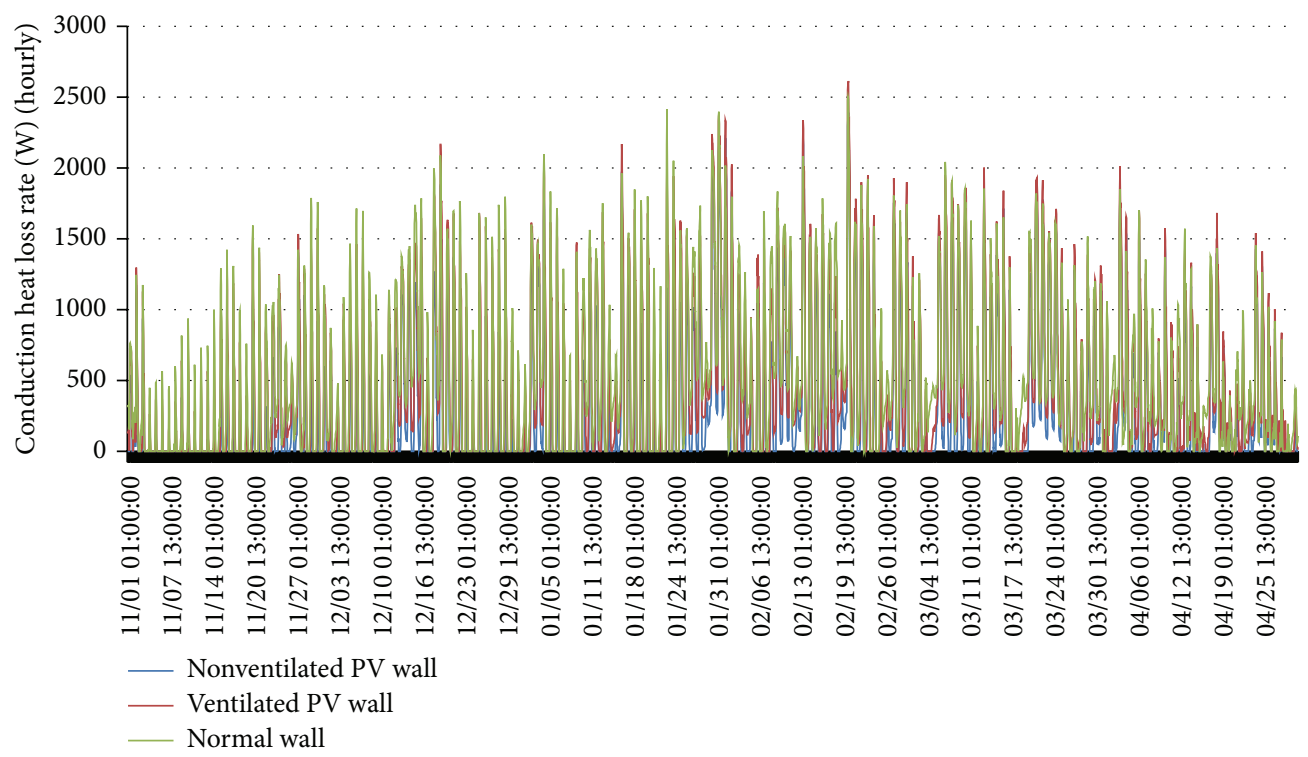

FIGURE 20: Comparison of the conduction heat loss rate between nonventilated PV wall and ventilated PV wall by simulation in winter.

PV panel on the electricity generation efficiency of the PV module would be dropped off while the PV conversion efficiency can be improved. However, in this study because the panel temperature difference of the two PV walls is small, the phenomenon is not obvious.

(2) At low latitudes similar to Zhuhai, China, in the building with south-facing PV wall compared to the one with normal wall, there is no obvious energy efficiency from the annual energy consumption of air conditioning, and if the air gap ventilation is ineffective, the cooling load of the building with PV wall will be higher than that of building with normal wall.

(3) At low latitudes similar to Zhuhai, China, in the design and construction of PV walls, we need to consider the length to thickness ratio of the air gap, which may influence the cooling effect of the PV panel. 


\section{Nomenclature}

\section{Abbreviations}

a-Si: $\quad$ Amorphous silicon

BAPV: Building-attached photovoltaics

BIPV: Building-integrated photovoltaics

DC: $\quad$ Direct current

PV module: Photovoltaic module

PV wall: Photovoltaic wall.

\section{Symbols}

T: Temperature $\left({ }^{\circ} \mathrm{C}\right)$.

\section{Subscripts}

\author{
a: $\quad$ Air gap \\ amb.: Ambient \\ p: Photovoltaic panel \\ bot.: At the bottom of the photovoltaic wall \\ mid.: At the middle of the photovoltaic wall \\ nv: Nonventilated PV wall \\ top: At the top of the photovoltaic wall \\ v: Ventilated PV wall.
}

\section{Conflict of Interests}

The authors declare that they have no financial and personal relationships with other people or organizations that can inappropriately influence their work. There are no professional or other personal interests of any nature or kind in any product, service, and/or company that could be construed as influencing the position presented in, or the review of, the paper.

\section{Acknowledgment}

This research was financially supported by the 12th FiveYear National Science \& Technology Support Program-Novel Technology of Comprehensive Utilization of Solar Energy (no. 2012BAA10B02).

\section{References}

[1] J. Q. Peng and L. Lu, "Investigation on the development potential of rooftop PV system in Hong Kong and its environmental benefits," Renewable \& Sustainable Energy Reviews, vol. 27, pp. 149-162, 2013.

[2] T. T. Chow, K. F. Fong, W. He, Z. Lin, and A. L. S. Chan, "Performance evaluation of a PV ventilated window applying to office building of Hong Kong," Energy and Buildings, vol. 39, no. 6, pp. 643-650, 2007.

[3] C. H. Peng, Y. Huang, and Z. S. Wu, "Building-integrated photovoltaics (BIPV) in architectural design in China," Energy and Buildings, vol. 43, no. 12, pp. 3592-3598, 2011.

[4] D. Infield, L. Mei, and U. Eicker, "Thermal performance estimation for ventilated PV façades," Solar Energy, vol. 76, no. 1-3, pp. 93-98, 2004.
[5] J. Q. Peng, L. Lu, H. X. Yang, and J. Han, "Investigation on the annual thermal performance of a photovoltaic wall mounted on a multi-layer façade," Applied Energy, vol. 112, pp. 646-656, 2013.

[6] J. Peng, L. Lu, and H. Yang, "An experimental study of the thermal performance of a novel photovoltaic double-skin facade in Hong Kong," Solar Energy, vol. 97, pp. 293-304, 2013.

[7] W. He, Y. X. Zhang, W. Sun, J. X. Hou, Q. Y. Jiang, and J. Ji, "Experimental and numerical investigation on the performance of amorphous silicon photovoltaics window in East China," Building and Environment, vol. 46, no. 2, pp. 363-369, 2011.

[8] Y. Wang, W. Tian, J. Ren, L. Zhu, and Q. Wang, "Influence of a building's integrated-photovoltaics on heating and cooling loads," Applied Energy, vol. 83, no. 9, pp. 989-1003, 2006.

[9] K. E. Park, G. H. Kang, H. I. Kim, G. J. Yu, and J. T. Kim, "Analysis of thermal and electrical performance of semitransparent photovoltaic (PV) module," Energy, vol. 35, no. 6, pp. 2681-2687, 2010.

[10] H. Radhi, "Energy analysis of façade-integrated photovoltaic systems applied to UAE commercial buildings," Solar Energy, vol. 84, no. 12, pp. 2009-2021, 2010.

[11] G. Y. Yun, M. McEvoy, and K. Steemers, "Design and overall energy performance of a ventilated photovoltaic façade," Solar Energy, vol. 81, no. 3, pp. 383-394, 2007.

[12] H. X. Yang, R. H. Marshall, and B. J. Brinkworth, "Validated simulation for thermal regulation of photovoltaic wall structures," in Proceedings of the 25th IEEE Photovoltaic Specialists Conference, May 1996.

[13] J. Jie, H. Wei, and H. N. Lam, “The annual analysis of the power output and heat gain of a PV-wall with different integration mode in Hong Kong," Solar Energy Materials and Solar Cells, vol. 71, no. 4, pp. 435-448, 2002.

[14] J. Jie, Y. Hua, H. Wei, P. Gang, L. Jianping, and J. Bin, "Modeling of a novel Trombe wall with PV cells," Building and Environment, vol. 42, no. 3, pp. 1544-1552, 2007.

[15] J. Jie, Y. Hua, P. Gang, and L. Jianping, "Study of PV-Trombe wall installed in a fenestrated room with heat storage," Applied Thermal Engineering, vol. 27, no. 8-9, pp. 1507-1515, 2007.

[16] Z. Zhu, H. Yang, R. Jiang, and Q. Wu, "Study on conjugate heat transfer in a photovoltaic wall," Acta Energiae Solaris Sinica, vol. 23, no. 1, pp. 49-54, 2002 (Chinese). 

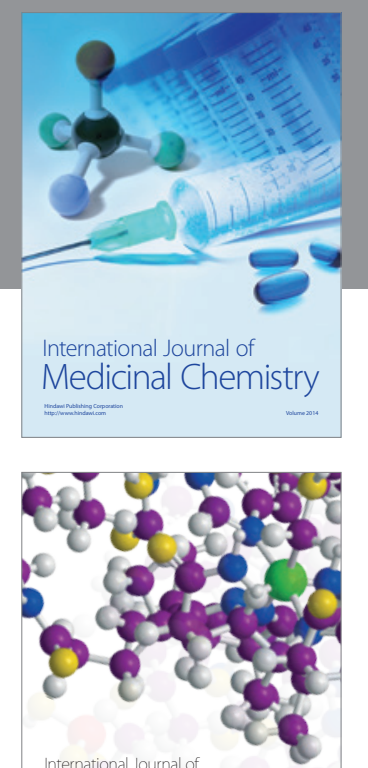

\section{Carbohydrate} Chemistry

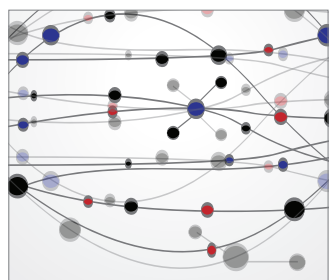

The Scientific World Journal
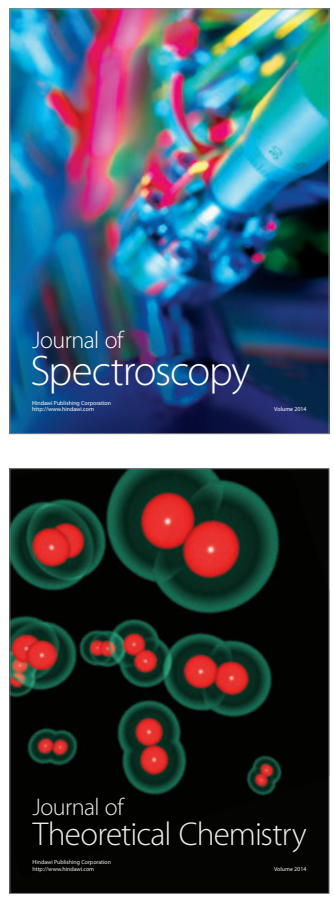
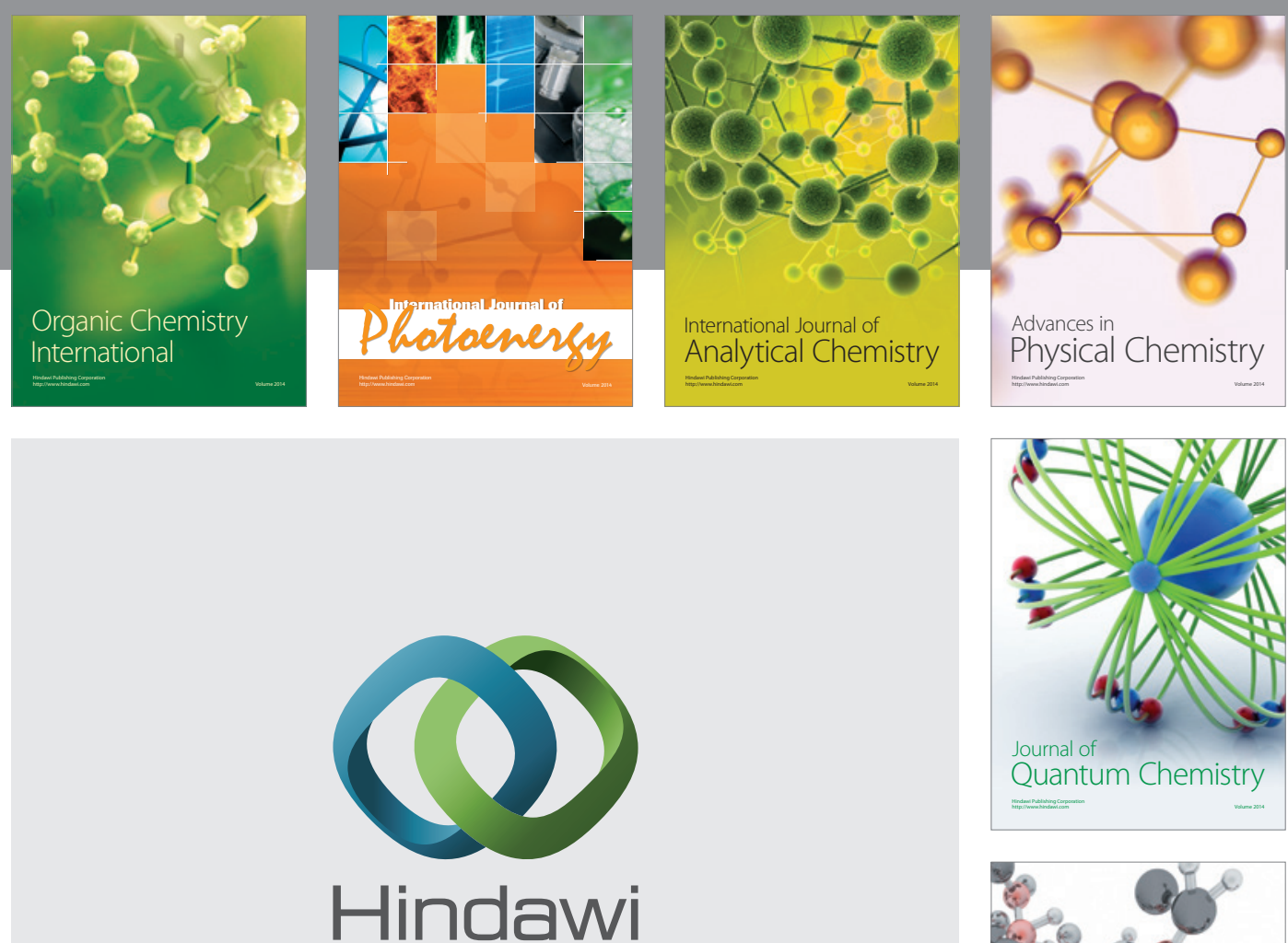

Submit your manuscripts at

http://www.hindawi.com

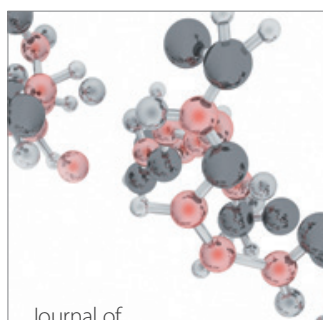

Analytical Methods

in Chemistry

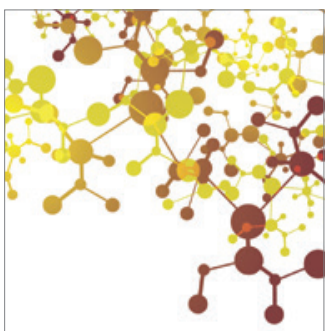

Journal of

Applied Chemistry

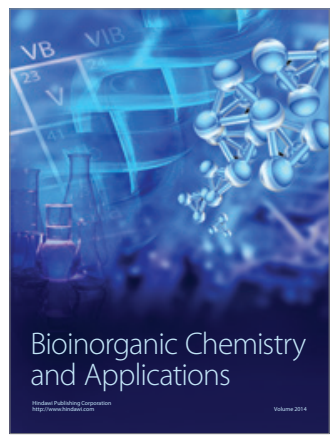

Inorganic Chemistry
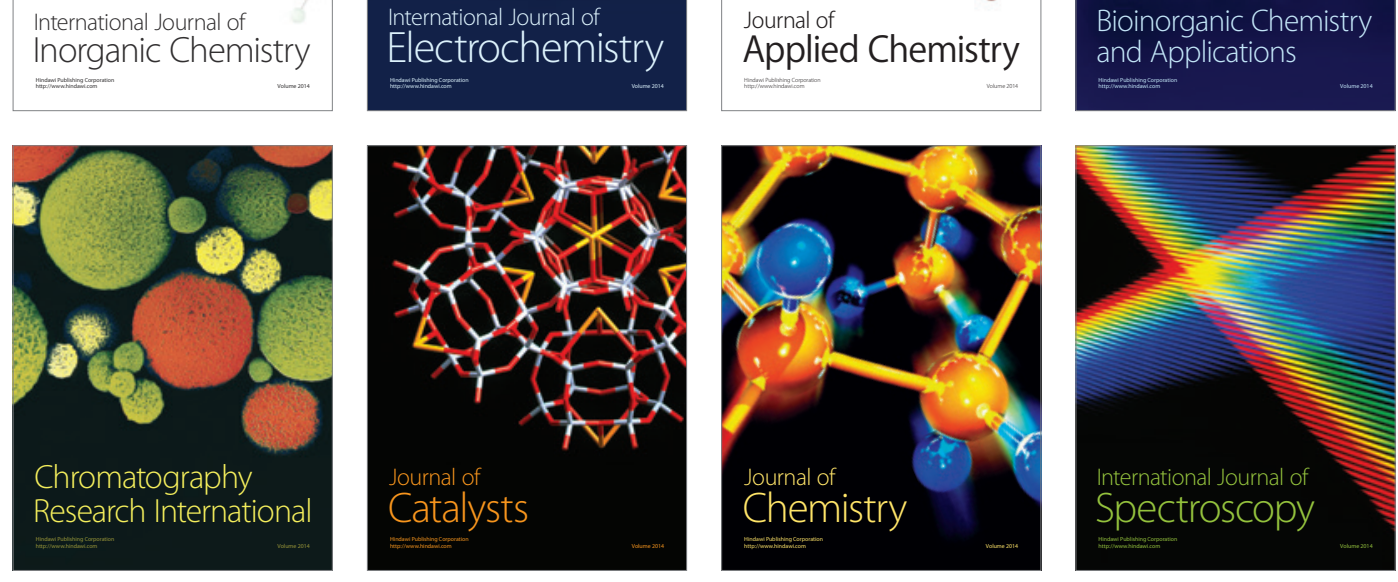